УДК 550. 83: 550. 814: 553: 41

\title{
ГЕОЛОГО-ГЕОФИЗИЧЕСКИЕ ОБСТАНОВКИ И ИНФОРМАТИВНОСТЬ ЭЛЕКТРОТОМОГРАФИИ НА ЗОЛОТОРУДНЫХ МЕСТОРОЖДЕНИЯХ СИБИРИ
}

\author{
Ерофеев Леонид Яковлевич 1 \\ Орехов Александр Николаевич1, \\ orekhovan@mail.tomsknet.ru \\ Гирякова Юлия Леонидовна', \\ ulg@tpu.ru \\ Ерофрева Галина Васильевна', \\ egv@mail.ru \\ 1 Национальный исследовательский Томский политехнический университет, \\ Россия, 634050, г. Томск, пр. Ленина 30.
}

\begin{abstract}
Актуальность исследования обусловлена необходимостью повышения эфффективности геофизических методов при поисках месторождений золота, в том числе за счёт использования новых методик проведения геофизических работ, в частности электроразведочной томографии вызванной поляризации. Для этой модификации электроразведки в настоящее время созданы теоретическая база, аппаратура, технологии измерений, обработки и интерпретации полевых наблюдений.

Цель: оценить информативность электротомографических работ при исследовании различных типов золоторудных месторождений.

Объекты: возможности электроразведочной томограффии при исследовании различных типов золоторудных объектов.

Результаты. На типичных полях месторождений золота Сибири и в их пределах - наиболее представительные в типовой градации рудоносные площади с достаточно подробно изученной геологической обстановкой и в пределах которых были выполнены геофизические сьёмки маситаба 1:2000-1:5000 (магнитометрия, электропрофилирование), проведены различные горные выработки, позволяющие привязать данные электротомографии к площадным геофизическим сьёмкам и геологии исследуемых профилей. Установлено, что на рудных полях всех физико-геологических типов с помощью электротомографрии можно достаточно уверенно оценивать толщину и состав покровных отложений, намечать места тектонических нарушений, определять основные черты структурного строения терригенно-осадочного комплекса пород в приповерхностных горизонтах, при благоприятных физико-геологических условиях прогнозировать местоположение оруденелых участков. Можно отметить, что наиболее информативным параметром, определяемым по материалам электротомографии в варианте вызванной поляризации, на всех физико-геологических типах золоторудных полей Сибирского региона является сопротивление пород, поляризуемость же их играет существенную роль лишь при локальной сульфидизации или графитизации пород.
\end{abstract}

\section{Ключевые слова:}

Электротомография, месторождения золота, Сибирский регион, тонкие квариево-жильные зоны, аномальные зоны.

\section{Введение}

Электроразведка на рудных полях золота Сибири применяется длительное время. Первые электроразведочные работы (методом изолиний) на золото в этом регионе были выполнены Н.И. Сафроновым в 1928 г. на Центральном месторождении в Мариинской тайге (Кузнецкий Алатау).

В настоящее время электроразведку в различных модификациях повсеместно широко используют при решении многих геологоразведочных задач практически на всех типах рудных полей золота [1]. Эффективность применения её различна. На месторождениях золота она проводится с различными масштабами наблюдения. Измерения выполняются по таким сетям, которые даже при самых детальных сьёмках не позволяют получить информацию о геологическом строении верхней части разреза, необходимую при детальном геокартировании рудоносных площадей, особенно на рудных полях золота Сибири, которые находятся в ареале вечно мёрзлых пород, где другие «поверхностные» методы, в том числе и геохимические, оказываются бессильными.
В последние десятилетия разработана новая технология производства полевых электроизмерений и интерпретации получаемых материалов, позволяющая существенно расширить возможности электроразведки при изучении верхней части разреза, которая пока не нашла должного места в общем комплексе геологоразведочных работ на золоторудных месторождениях. Речь идёт об электротомографии [2-6]. Для этой модификации электроразведки в настоящее время созданы теоретическая база, аппаратура, технологии измерений, обработки и интерпретации полевых наблюдений [7-10]. Её сейчас широко используют главным образом при проведении инженерногеологических, археологических, экологических и гидрогеологических изысканий [11-20]. В рудных районах и, в частности, при изучении золотоносных площадей в России сделаны лишь отдельные шаги. Они, как и зарубежный опыт, свидетельствуют о широких потенциальных возможностях электротомографии при изучении рудных площадей.

В настоящей работе рассматриваются результаты многолетних исследований информативности электротомографии в типичных физико-геологических 
обстановках золоторудных месторождений Сибирского региона.

Многочисленные месторождения золота Сибири сосредоточены в основном в складчатом обрамлении Западно-Сибирской платформы, с геофизических позиций они делятся на четыре группы по типу пород, слагающих рудные поля: на месторождения, расположенные в углеродисто-терригенных (черносланцевых) толщах; месторождения, локализованные в интрузивных образованиях; месторождения, сформированные в приконтаковых (скарновых) зонах; месторождения, находящиеся в терригенно-осадочных флишоидных отложениях [4].

Для определения возможностей электротомографии при изучении того или иного физикогеологического типа месторождений золота были выбраны разноландшафтные, наиболее значимые в промышленном отношении золоторудные провинции Сибири, а в их пределах - наиболее представительные в типовой градации рудоносные площади с достаточно подробно изученной геологической обстановкой и в пределах которых были выполнены геофизические съёмки масштаба 1:2000-1:5000 (магнитометрия, электропрофилирование), проведены различные горные выработки, позволяющие привязать данные электротомографии к площадным геофизическим съёмкам и геологии исследуемых профилей.

\section{Месторождения золота в черносланцевых толщах}

Месторождения этого типа, как правило, приурочены к мощным (до сотен метров) отложениям геосинклинальных комплексов, возраст которых обычно оценивается в интервале от протерозоя до нижнего палеозоя. Типоморфной особенностью этих толщ является наличие углеродистых сланцев. Они, как правило, сульфидизированы. Кроме того, в них произошла существенная дифференциация физических свойств пород, главным образом за счёт избирательной графитизации обуглероженных отложений и обогащения их сульфидами различных металлов (чаще всего пиритом). С такими участками обычно связано золотое оруденение, которое часто пространственно приурочено к изгибам складок, образованных из этих отложений.

В Сибирском регионе к рассматриваемому типу относятся крупнейшие месторождения золота России, расположенные в пределах Енисейского кряжа (Олимпиадинское, Благодатное и др.), Ленской золоторудной провинции (Сухой Лог и др.), Восточного и Западного Саяна (Зун-Холбинское, месторождения Ольховско-Чибижекской группы и др.), а также ряда других рудных провинций Сибири, Забайкалья и ближнего зарубежья.

Опытно-методические работы по выяснению возможностей электротомографии в пределах таких месторождений выполнены в Бодайбинском золоторудном районе, территориально относящемся к Ленской провинции, с которой связан целый ряд ранее известных и недавно открытых, в том числе в процессе проведения работ, месторождений и рудопроявлений. К основным можно отнести месторождения Сухой
Лог, Высочайший, Вернинское, Красный, Чёртово Корыто, Невское и др.

Исследования возможностей электротомографии выполнены в пределах нескольких рудных полей. Для полевых измерений использовалась десятиканальная многоэлектродная станция Syscal-ProSwitch 72 фирмы IrisInstruments. Измерения выполнялись в варианте вызванной поляризации с определением параметра поляризуемости и удельного электрического сопротивления среды.

Исследуемые рудные поля сложены в различной степени обуглероженными и сульфидизированными терригенно-осадочными отложениями рифейсковендского возраста, которые представлены различными сланцами, алевролитами и песчаниками. Четвертичные отложения часто занимают до 60 \% площади, преобладают закрытые ландшафты - залесённые и задернованные склоны с моховым слоем, часто имеющим мощность до 1 м и более, под которым развит вечномёрзлый слой гумусо-торфяных отложений, делювиально-солифлюкционных образований. Значительную площадь занимают поля курумов.

В статье приведены результаты исследований в пределах трёх участков с известным геологическим строением, с характерными для данного региона геологическими обстановками.

На участках, где приповерхностные горизонты представлены породами, практически стерильными в отношении углеродистого вещества и (или) сульфидов, основную информацию о геологическом строении даёт удельное электрическое сопротивление. На разрезах КС, полученных по результатам двумерной инверсии, уверенно выделяются четвертичные отложения с контрастной нижней границей. Отчётливо просматривается неоднородность их состава, связанная с особенностями распределения в пространстве участков с вечномёрзлыми породами и курумом, границы между литологическими разностями пород и местоположение тектонических нарушений (по смещению границ) (рис. 1). Подчеркнём, что при обычных детальных (масштаба 1:2000) геофизических съёмках отмеченные элементы и черты геологического строения не находят заметного отражения в наблюдаемых полях.

В качестве примера на рис. 2, $a$ приведены результаты электротомографических измерений по одному из опытных профилей. Томографический профиль пересекает ранее выявленную рудную зону. В геологическом отношении она представлена интенсивно обуглероженными сланцами, филлитами, а также песчаниками. Разрез перекрыт достаточно мощным курумом, который, как видно на рис. 2, a, весьма четко выделяется в разрезе первым слоем высоких сопротивлений, ниже его, не менее контрастно проявляется слой вечной мерзлоты, глубже разрез по данным электротомографии не дифференцируется. Последнее обусловлено высокой электропроводимостью нижней части разреза, в которой не проявляются не только литологические разности пород, но и оруденелые участки. Контур одного из них показан (в виде эллипса) на рис. 2, б. В таких условиях практически сво- 
дится к нулю и возможность исследовать разрез по поляризуемости. Широкое развитие интенсивно обуглероженных и сульфидизированных пород при- водит к тому, что измеряемые сигналы крайне малы, что делает невозможным уверенную инверсию полученных данных

a/a
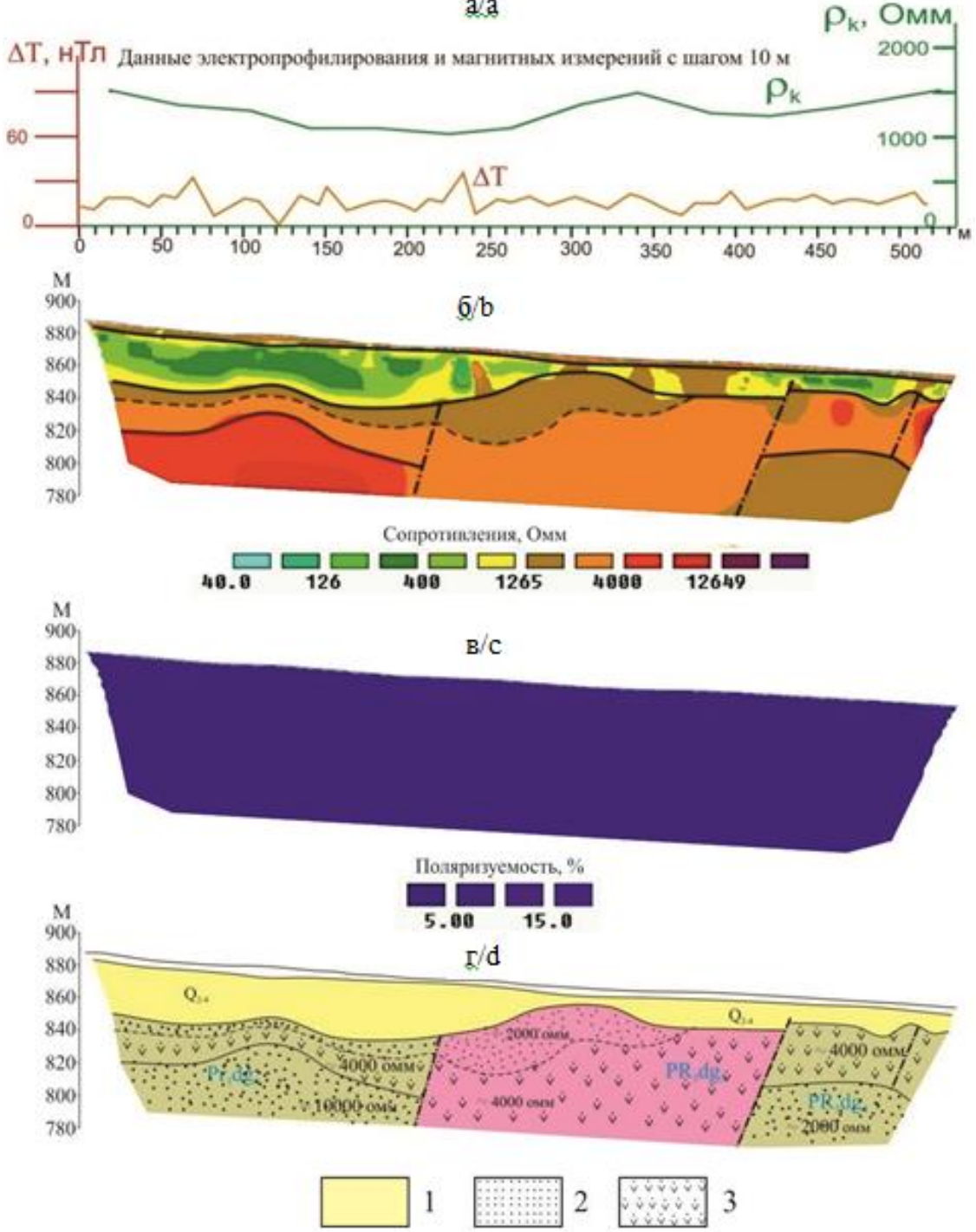

Рис. 1. Результаты геофизических работ на профиле № 1 (Бодайбинский золоторудньй район): а) графики электропрофилирования ( $\left.\rho_{k}\right)$ симметричной установкой и индукиии магнитного поля (АT). Шаг наблюдений - 10 м; б, в) разрезы кажущегося сопротивления $\left(\rho_{k}\right)$ и поляризуемости $\left(\eta_{k}\right)$ соответственно по данным электроразведочной томографии; г) схематический геологический разрез по результатам интерпретачии. По параметру поляризуемости разрез не дифференцируется. 1 - четвертичные отложения; 2 -мелкозернистые песчаники; 3 - полимиктовые песчаники

Fig. 1. Results of geophysical surveys, profile no. 1 (Bodaibo gold ore area): a) graphs of symmetrical electrical profiling $\left(\rho_{k}\right)$ and magnetic induction $(\Delta T)$. Measurement interval $\left.-10 \mathrm{~m} ; \mathrm{b}, \mathrm{c}\right)$ sections of apparent resistivity $\left(\rho_{k}\right)$ and polarizability $\left(\eta_{k}\right)$, respectively, according to electrical tomography data; d) schematic geological section plotted according to interpretation results. The section is not differentiated by polarizability. 1 - Quaternary formations; 2 fine-grained sandstones; 3 - polymictic sandstones

На участках, где степень обуглероженности у разных пород различна, возможности электротомографии в изучении коренных пород в близповерхностных горизонтах существенно возрастают. С ее помощью уверенно картируется структурное строение отложений и проявления в них тектонических воздействий. Но только по величине кажущихся сопротивлений и по параметру поляризуемости пород разрез и в этих условиях практически не расчленяется. Для примера на рис. 2, a приведены результаты электротомографических работ на участке Кяхтинский по профилю, пересекающему ось складки, в ядре которой сформирована пиритизированная золотоносная зона. По приведенному разрезу можно видеть, наряду с прочим, форму замка складки, оценить её размеры и глубину залегания, а также наметить местоположение тектонических нарушений в осадочном комплексе пород по смещению границ слоёв, выделяемых в разрезе кажущихся 
сопротивлений. Собственно рудное тело в складке по сопротивлению не отмечается, а по параметру поляризуемости разрез вообще не расчленяется.

\section{Месторождения в интрузивных породах}

Месторождения золота этого физико-геологического типа представлены чаще всего кварцево-жильными телами с различным содержанием сульфидов. В Сибири рудные поля этого типа распространены наиболее широко и известны практически во всех складчатых регионах Сибири, Забайкалья и Дальнего Востока

По содержаниям сульфидов в руде среди месторождений этого типа выделяют: существенно сульфидные, умеренно сульфидные и малосульфидные. Большая часть месторождений золота Сибири относится к малосульфидным и умеренно сульфидным типам. Их рудные тела представлены, как правило, тонкими кварцево-жильными зонами [1].

Исследование возможностей электротомографии для этого типа месторождений выполнены в Мрасском 30- лоторудно-россыпном районе Кузнецкого Алатау. Измерения проведены в варианте ВП на Беловской площади по буровому профилю (скв. 1-4), вдоль которого пройдена протяженная траншея (около 400 м) (рис. 3).

Эти горные выработки вскрыли дайки диабазового состава, золото-кварцевые жилы и прожилки, зоны березитизации и незалеченные тектонические нарушения. При сопоставлении геологического разреза с разрезом кажущегося сопротивления однозначно можно установить соответствие только самых верхних частей разрезов. Очевидно, что на полученном по результатам двумерной инверсии разрезе более или менее уверенно можно геометризовать только структурную кору выветривания, а также область других гипергенных изменений. Отдельно необходимо отметить отсутствие контрастной границы между перекрывающими отложениями и структурной корой выветривания. Выделяется только градиентный переход между этими зонами
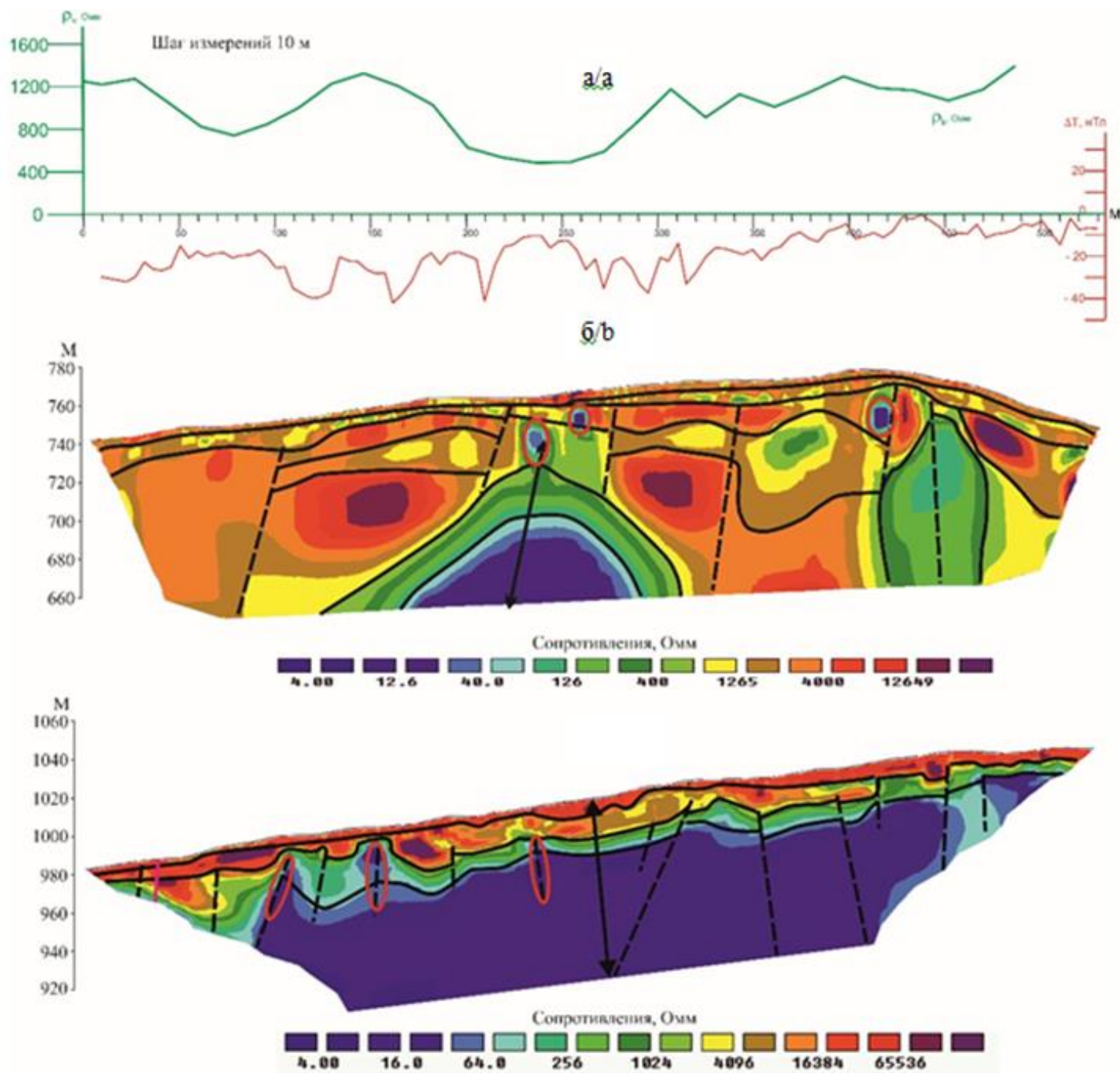

Pис. 2. Разрезы электросопротивления на участке с избирательной (а) и сплошной интенсивной графитизацией (б) в пределах Бодайбинского района Ленской золоторудной провинции. По величине поляризуемости пород разрезы не дифферениируются

Fig. 2. Electrical resistivity sections obtained in selective (a) and continuous intensive graphitization (b) area within the Bodaibo gold ore area of the Lena gold-ore province. These actions are not differentiated by rock polarizability 

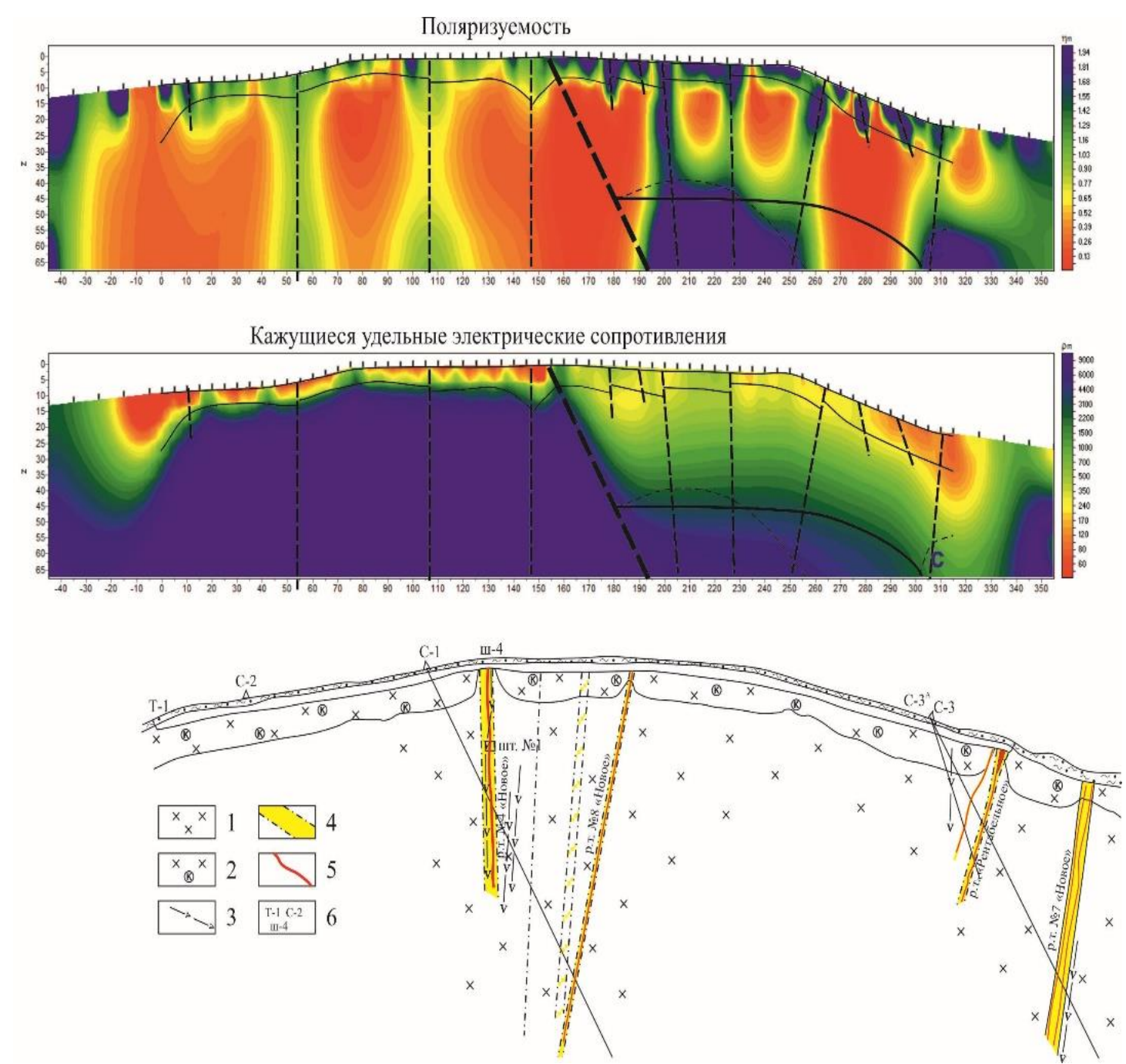

Рис. 3. Разрезы электросопротивления и поляризуемости по данным электроразведочной томографии в пределах золоторудного поля, локализованного в интрузивном массиве (Горная Шория) и геологический разрез по даннымм бурения и горных работ: 1 - диориты, квариевые диориты, 2 - структурная кора выветривания по диоритам, 3 - дайки диабазов и диабазовых порфиритов, 4 - березиты, 5 - кварцевые жиль и прожилки, 6 горные выработки

Fig. 3. Electric resistivity and polarizability sections plotted according to the data of electrical tomography in gold-ore field hosted in the intrusive rock sequence (Gornay Shoria) and a geological section according to the data from drilling and mining operations: 1 -diorites, quartz diorites, 2 -diorite weathered layer, 3 -diabase and diabaseporphyrite dikes, 4 - beresites, 5 - quartz veins and veinlets, 6 - mining operations

Какие-либо другие элементы геологического строения (в том числе жилы, нарушения и т. д.) на разрезе не выделяются. Возможная причина этого может состоять в том, что золотокварцевые жилы, как и дайковые тела, зоны березитизации пород и вмещающие гранодиориты разрушены, превратились вместе в относительно однородную (с точки зрения электропроводимости) среду, чему в немалой степени способствует обводненность этой части разреза.

По параметру поляризуемости разрез и в этом случае практически не дифференцируется. Величина кажущейся поляризуемости пород изменяется здесь без каких-либо видимых закономерностей в незначительных пределах - 0,2-1,5\%. Исключение составляют субвертикальные линейные зоны, которые достаточно хорошо совпадают с известными тектоническими нарушениями и жилами.

\section{Месторождения золота контактовых зон}

Месторождения золота этого типа приурочены к контакту между терригенными породами и интрузивными образованиями и, как правило, представлены скарнами и скарноидами.

Чаще всего к сибирским месторождениям этого типа относят Синюхинское, Мурзинское, Фёдоровское, Чайское, Наталинское, Тардан, МайскоЛебединское, Ульменское, Югалинское, Южное и другие месторождения и рудопроявления.

В Забайкалье скарновыми считаются Юбилейное, Андрюшинское, Быстринское, Желанное, Урюмканское и другие месторождения и рудопроявления.

Для скарновых месторождений, как правило, характерна полигенная минерализация. Наиболее ранняя минерализация является высокотемпературной. 
Она непосредственно связана со скарнами (в том числе и генетически).

Более поздняя минерализация в основном является средне- и низкотемпературной. Для неё характерно отсутствие явно выраженной связи со скарнами. Как правило, она представляет собой золото-кварц-сульфидное оруденение, часто локализованное в тонких трещинах. Возможности электротомографии при разведке жильного оруденения скарновых месторождений рассмотрены в предыдущем разделе настоящей статьи, ниже речь пойдёт о высокотемпературной минерализации.

Рудные тела высокотемпературной минерализации являют собой объёмы скарнированных пород, в которых сформирована вкрапленная руда, состоящая из сульфидов, являющихся, как известно, в большинстве своём, хорошими проводниками электрического тока. Однако это обстоятельство не приводит к низкоомно- сти рудных тел из-за того, что вкрапленники золотосодержащих сульфидов изолированы друг от друга вмещающей высокоомной средой. Поэтому рудные тела высокотемпературной генерации практически не проявляются в поле электросопротивления на фоне скарнированных пород, которые представляются сравнительно однородными высокоомными образованиями, уверенно выделяемыми в разрезе по данным электротомографии (рис. 4, б). В противоположность этому по параметру поляризуемости участки скарнированных пород не отличаются от других массивов пород, слагающих рудоносную площадь, но рудные тела по параметру поляризуемости находят своё отражение в виде локальных аномалий повышенной поляризуемости (рис. 4, в). Это является ярким примером классического сочетания методов сопротивления и вызванной поляризации.
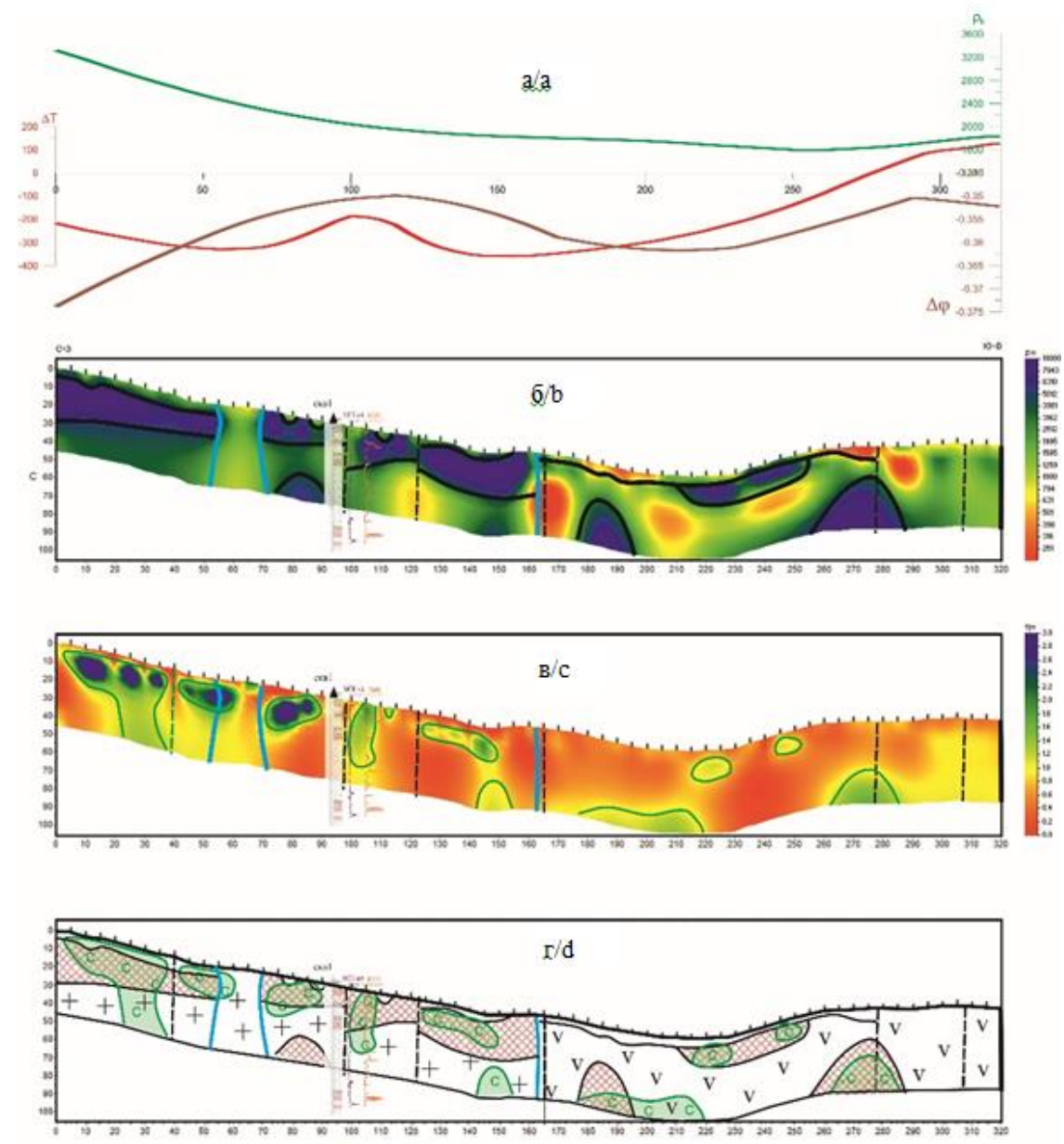

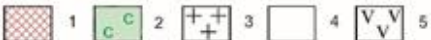

Рис. 4. Результаты геофизических измерений и сопоставление их с геологическими данными на Ийской площзади в Западных Саянах. Условные обозначения: а) графики кажущегося электрического сопротивления, приращеения индукции магнитного поля и угла сдвига фазы; б) разрез по величине электрического сопротивления пород; в) разрез по величине поляризуемости; г) схематический геологический разрез, в котором: 1 - рудные тела в зоне скарнирования пород; 2 - рассеянная сульфидизация; 3 - гранодиориты; 4 - делювиальные отложения; 5 - вулканогенные осадочные породы

Fig. 4. Results of geophysical measurements and their correlation with geological data obtained in the Iyskoe area in the Western Sayan Legend: a) graphs of apparent electrical resistivity, increment of magnetic induction and phase angle; b) sectional view of electrical resistivity of rock; c) sectional view of polarizability; d) schematic geological section, in which: 1 - ore bodies in skarnatization zone; 2 - disseminated sulphide mineralization; 3 - granodiorites; 4 talus deposits; 5 - volcanogenic sedimentary rocks 


\section{Золоторудные месторождения}

\section{терригенно-осадочных флишоидных толщ}

Как и скарновые месторождения, объекты этого типа в большинстве своём известны в Сибири (Советское, Эльдорадо и др.) и Забайкалье (Тасеевское, Любавинское и др.).

Месторождения золота в флишоидных толщах представлены чаще всего минерализованными зонами и гнездамии обычно относятся к кварц-золотосульфидной формации [1].

Характерной особенностью таких месторождений, с точки зрения электропроводимости слагающих пород, является то, что углистое вещество не играет здесь существенной роли в электропроводимости геологической среды. Аномальные эффекты на рудных полях обуславливаются главным образом содержанием сульфидов (понижающих сопротивление) и интенсивностью окварцевания пород (повышающих электросопротивление). Как правило, такие аномальные участки соседствуют, совмещаются друг с другом, являются важным поисковым признаком для электроразведки.
На рис.5 показаны результаты электротомографии в варианте вызванной поляризации, полученные в Салаирском кряже на Ельской рудоносной площади. В разрезах по сопротивлению и поляризуемости пород в северо-восточной части профиля исследований четко проявляется аномальная зона, соответствующая рудному телу. По поляризуемости она однородна, по сопротивлению распадается на две части: на участок аномально повышенного и сопряженного с ним пониженного сопротивления. В поле поляризуемости эта зона однородна потому, что прокварцованный участок пород, который четко выделятся повышенным сопротивлением, содержит рассеянную минерализацию - пиритизирован. В центральной части профиля аномалия поляризуемости обусловлена повышенной обводненностью в значительной мере разрушенных пород, что подтверждается геологическими данными. На рис. 5 закартировано тектоническое канализирующее верховодку нарушение, которое, кстати, фиксируется и в поле сопротивлений по «проседанию» в этом месте коры выветривания.
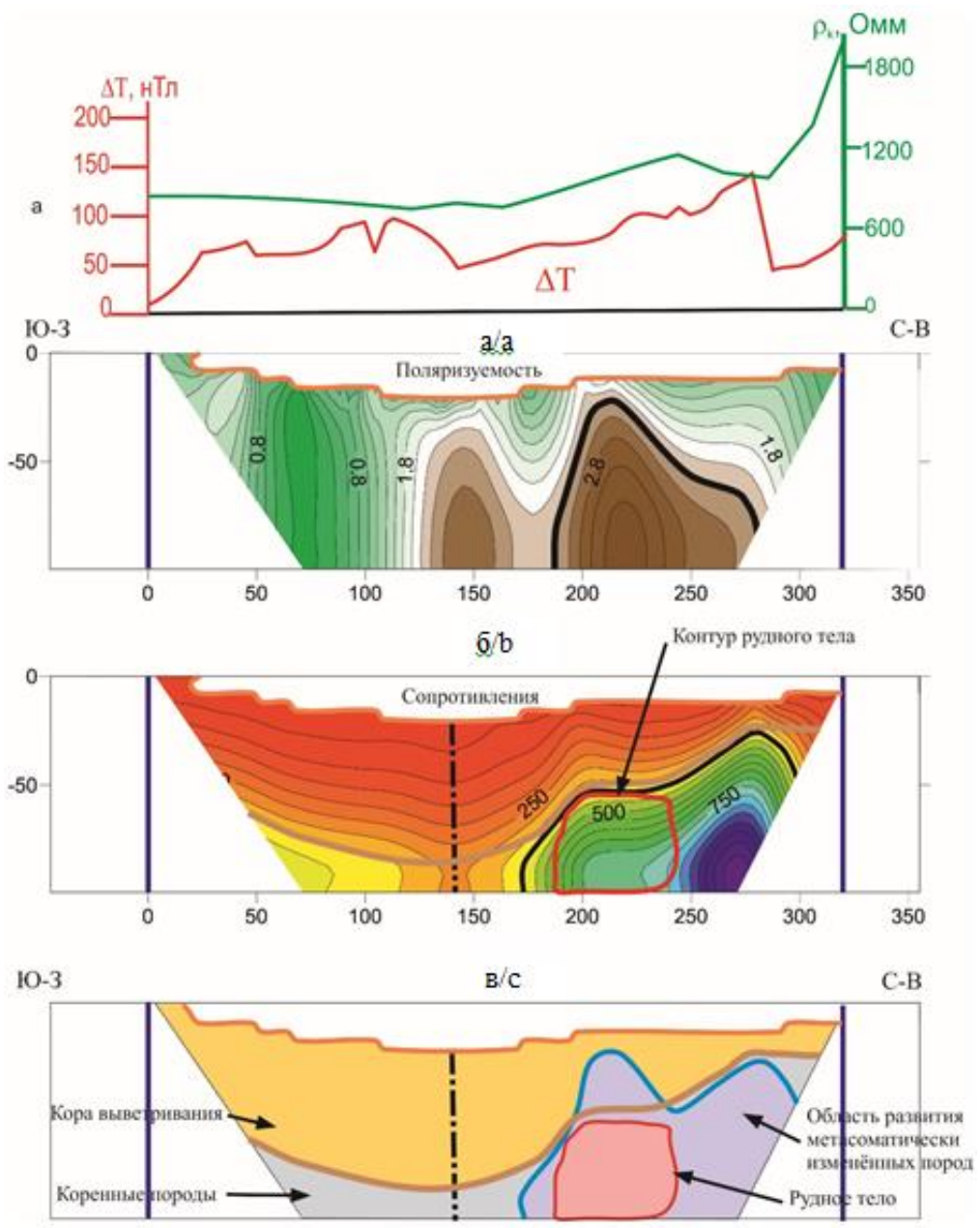

$\mathrm{r} / \mathrm{d}$

Рис. 5. Графики кажущегося сопротивления и приращения полного вектора индукции магнитного поля (а), разрезы угла сдвига фазы (б) и кажущегося электрического сопротивления (в) по данным электроразведочной томографии и интерпретационный геологический разрез (2) на Ельской золоторудной площади (Салаирский кряж)

Fig. 5. Results of geophysical measurements, conducted in the Yelskaya gold-bearing area of the Salairsky Ridge: a) graphs of apparent resistivity and increment of total vector of magnetic induction; b) polarizability and c) apparent electrical resistivity sections plotted according to electrical tomography data; d) interpretation geological section 


\section{Заключение}

Электротомография позволяет решать в разной мере (в зависимости от физико-геологических условий) ряд практически важных задач при изучении геологического строения верхней части разреза золоторудных месторождений. При этом мы получаем возможность выделения таких элементов строения разреза, которые не могут быть получены при площадных электроразведочных работах, выполняемых методом электропрофилирования.

Наиболее информативным параметром, определяемым по материалам электротомографии в варианте вызванной поляризации, на всех физико-

\section{СПИСОК ЛИТЕРАТУРЬ}

1. Методическое руководство по оценке прогнозных ресурсов алмазов, благородных и цветных металлов. Выпуск «Золото»/ под ред. Б.И. Беневольский, С.С. Вартанян. - М.: Изд-во Центрального научно-исследовательского геологоразведочного института цветных и благородных металлов, 2010. - 182 с.

2. Многоэлектродные электрические зондирования в условиях горизонтально-неоднородных сред / А.А. Бобачев, И.Н. Модин, Е.В. Перваго, В.А. Шевнин // Разведочная геофизика. 1990. - T. 2. - C. 17-21.

3. Опыт применения электротомографии в геофизике / Е.В. Балков, Г.Л. Панин, Ю.А. Манштейн, А.К. Манштейн, В.А. Белобородов // Геофизика. - 2012. - № 6. - С. 54-63.

4. Ерофеев Л.Я., Орехов А.Н. Геолого-геофизические условия на золоторудных полях Сибири // Известия Томского политехнического университета. - 2014. - Т. 324. - № 1. - С. 80-85.

5. Szala S., Szarka L. On the classification of surface geoelectric arrays // Geophysical Prospecting. - 2008. - № 56. - P.159-175.

6. Griffaths D.H. Two-dimensional resistivity imaging and modeling in areas of complex geology // Journal of Applied Geophysics. 1993. - № 29. - P. 211-226.

7. Dahlin T., Zhou B.A Numerical comparison of 2D resistivity imaging with ten electrode arrays // Geophysical Prospecting. 2004. - № 52. - P. 379-388.

8. Loke M.H., Barker R.D. Practical techniques for 3D resistivity surveys and data inversion techniques // Geophysical Prospecting. - 1996. - V. 44. - № 3. - P. 499-524.

9. Loke M.H., Barker R.D. Rapid least-squares inversion of apparent resistivity pseudosections by a quasi-Newton method // Geophysical Prospecting. - 1996. - V. 44. - № 4. - P. 131-152.

10. Dahlin T. The development of electrical imaging techniques // Computers and Geosciences. - 2001. - V. 27. - № 9. - P. 1019-1029.

11. Dahlin T., Byeim H., Svensson C. Use of electrical imaging in site investigations for a railway tunnel enough the Highlands Horst, Smolen, Guarantee // Journal of Engineering Geology. - 1999. V. 32. - № 2. - P. 163-173. геологическихтипах золоторудных полей Сибирского региона является сопротивление пород, поляризуемость же их играет существенную роль лишь при локальной сульфидизации или графитизации среды.

Таким образом, говоря об оценке роли, места и возможностей электроразведочной томографии методом вызванной поляризации при изучении разнотипных золоторудных месторождений, нужно констатировать, что эти работы должны выполнятся в пределах детальных перспективных участков, выявленных по результатам площадных работ, а их основное назначение - детальная характеристика разреза (в том числе оруденения) на этапе подготовки под бурение.

12. Pellerin H. Applications of electrical and electromagnetic methods for environmental and geotechnical investigations // Surveys in Geophysics. - 2003. - № 23. - P. 106-133.

13. Barker R., Moore J. The application of time lapse electrical tomography in groundwater studies // The Leading Edge. - 1988. № 10. - P. 1454-1456.

14. Candansayar M.E., Basokur A.T. Detection small-scale targets by the 2D inversion of two-sided three-electrode data: application to an archeological survey // Geophysical Prospecting. - 2001. № 49. - P. 40-58.

15. Dahlin T. 2D resistivity surveying for environ-mental and engineering applications // First Break. - 1996. - № 14. - P. 275-283.

16. Электромагнитное профилирование компактной аппаратурой: новый подход и результаты применения / Ю.Г. Карин, Е.В. Балков, Д.И. Фадеев, А.К. Манштейн, Г.Л. Панин, А.О. Алымов, Д.Б. Романов // Вестник Новосибирского государственного университета. Серия: Информационные технологии. 2018. - T. 16. - № 4. - C. 68-78.

17. Tarasov V.A., Lukhmanov V.L. Deep resistivity and Ip tomography for ore exploration // European Association of Geoscientists \& Engineers Conference Proceedings. - Engineering and Mining Geophysics. - 2018. - V. 2018. - P. 1-6.

18. The dynamics of gold in regolith change with differing environmental conditions over time / R. Anand, M. Lintern, R. Hough, R. Noble, M. Verrall, W. Salama, J. Balkau, N. Radford // Geology. - 2017. - V. 45. - № 2. - P. 127-130.

19. Калибровка и экспресс-трансформация сигналов компактной аппаратуры малоглубинного электромагнитного профилирования / Д.И. Фадеев, Е.В. Балков, Г.Л. Панин, Ю.Г. Карин // Геофизика. - 2018. - № 2. - С. 52-57.

20. Орехов А.Н., Амани М.М. Возможности геофизических методов для прогнозирования трещиноватости коллекторов // Известия Томского политехнического университета. Инжиниринг георесурсов. - 2019. - Т. 330. - № 6. - С. 198-209.

Поступила: 27.03.2019 2.

\section{Информация об авторах}

Ерофеев Л.Я., доктор геолого-минералогических наук, профессор Отделения геологии Инженерной школы природных ресурсов Национального исследовательского Томского политехнического университета.

Орехов A.H., кандидат геолого-минералогических наук, доцент отделения геологии Инженерной школы природных ресурсов Национального исследовательского Томского политехнического университета.

Гирякова Ю.Л., кандидат педагогических наук, ассистент Отделения экспериментальной физики Инженерной школы ядерных технологий Национального исследовательского Томского политехнического университета.

Eрофеева Г.В., доктор педагогических наук, профессор Отделения экспериментальной физики Инженерной школы ядерных технологий Национального исследовательского Томского политехнического университета. 
UDC 550.83: 550. 814: 553: 41

\section{GEOLOGICAL-GEOPHYSICAL ENVIRONMENTS AND EFFICIENCY OF ELECTRICAL TOMOGRAPHY IN SIBERIAN GOLD ORE DEPOSITS}

Leonid Ya. Erofeev1

\section{Alexander N. Orekhov'1,}

orekhovan@mail.tomsknet.ru

\section{Yuliya L. Giryakova ${ }^{1}$,}

ulg@tpu.ru

\section{Galina V. Erofeeva1, egv@tpu.ru} 1 National Research Tomsk Polytechnic University,
30, Lenin avenue, Tomsk, 634050, Russia.

The relevance of the research is caused by the need to improve the efficiency of geophysical methods in the search for gold ore fields, including the use of new methods of geophysical work, electrical tomography VP particularly. Theoretical base, instrumentation, measurement, processing and field interpretation technologies have currently been developed for this method of geoelectric prospecting The main aim of the research is to estimate the informativeness of induced polarization tomography in typical physical-geological environments of Siberian gold ore fields.

Objects of the research are opportunities of the electrical tomography during the exploration of different types of gold ore fields. Method of the research is the electrical tomography.

Results. It has been found that in ore fields of all physical-geological types, electrical tomography can be used with sufficient assurance to evaluate the thickness and composition of overburden rocks, to locate tectonic faults, to determine the main features of the structural framework of terrigenous-sedimentary rocks in the subsurface horizons, and to make location prognosis for ore mineralization in favourable physical-geological environments. The most informative parameter determined by the data of induced polarization tomography in all types of physical-geological gold ore fields of the Siberian region is rock resistivity, whereas their polarizability is significant, provided that local sulphidization or graphitization of rocks is present.

\section{Key words:}

Electrical tomography, gold ore deposits, Siberian territory, thin quartz-vein zones, anomalous zones.

\section{REFERENCES}

1. Methodicheskoe rukovodstvo po otsenke prognoznykh resursov almazov, blagorodnykh i tsvetnykh metallov. Zoloto [Methodological guidelines for assessment of forecast resources of diamonds, precious and non-ferrous metals. Gold]. Eds. B.I. Benevolskiy, S.S. Vartanyan. Moscow, Central Research Geological Exploration Institute of non-ferrous and noble metals Publ. house, 2010. $182 \mathrm{p}$.

2. Bobachev A.A., Modin I.N., Pervago E.V., Shevnin V.A Mnogoelectrodnye electricheskie zondirovaniya v usloviakh gorizontalno-neodnorodnykh sred [Multielectrode electric sounding in the conditions of horizontally inhomogeneous media]. Razvedochnaya geofizika, 1990, vol. 2, pp. 17-21.

3. Balkov E.V., Panin G.L., Manshtein Yu.A., Manshtein A.K., Beloborodov V.A. Opyt primeneniya electrotomografii v geofizike [Electrotomography in the geophysics]. Geofizika, 2012, vol. 6, pp. 54-63.

4. Erofeev L.Ya., Orekhov A.N. Geological and geophysical conditions at Siberian golden ore fields. Bulletin of the Tomsk Polytechnic University, 2014, vol. 324, no. 1, pp. 80-85. In Rus.

5. Szala S., Szarka L. On the classification of surface geoelectric arrays. Geophysical Prospecting, 2008, no. 56, pp. 159-175.

6. Griffaths D.H. Two-dimensional resistivity imaging and modeling in areas of complex geology. Journal of Applied Geophysics, 1993 no. 29 , pp. 211-226.

7. Dahlin T., Zhou B.A Numerical comparison of 2D resistivity imaging with ten Electrode arrays. Geophysical Prospecting, 2004, no. 52, pp. 379-388.

8. Loke M.H., Barker R.D. Practical techniques for 3D resistivity surveys and data inversion techniques. Geophysical Prospecting, 1996, vol. 44, no. 3, pp. 499-524.

9. Loke M.H., Barker R.D. Rapid least-squares inversion of apparent resistivity pseudosections by a quasi-Newton method. Geophysical Prospecting, 1996, vol. 44, no. 4, pp. 131-152.
10. Dahlin T. The development of electrical imaging techniques. Computers and Geosciences, 2001, vol. 27, no. 9, pp. 1019-1029.

11. Dahlin T., Byeim H., Svensson C. Use of electrical imaging in site investigations for a railway tunnel enough the Highlands Horst, Smolen, Guarantee. Journal of Engineering Geology, 1999, vol. 32, no. 2, pp. 163-173.

12. Pellerin H. Applications of electrical and electromagnetic methods for environmental and geotechnical investigations. Surveys in Geophysics, 2003, no. 23, pp. 106-133.

13. Barker R., Moore J. The application of time lapse electrical tomography in groundwater studies. The Leading Edge, 1988, no. 10 , pp. $1454-1456$

14. Candansayar M.E., Basokur A.T. Detection small-scale targets by the 2D inversion of two-sided three-electrode data: application to an archeological survey. Geophysical Prospecting, 2001, no. 49, pp. $40-58$.

15. Dahlin T. 2D resistivity surveying for environ-mental and engineering applications. First Break, 1996, no. 14, pp. 275-283.

16. Karin Yu.G., Balkov E.V., Fadeev D.I., Manshtein A.K., Panin G.L., Alymov A.O., Romanov D.B. Electromagnetic profiling by compact equipment: a new approach and application results. Bulletin of Novosibirsk State University. Information technology, 2018, vol. 16, no. 4, pp. 68-78. In Rus.

17. Tarasov V.A., Lukhmanov V.L. Deep resistivity and Ip tomography for ore exploration. European Association of Geoscientists \& Engineers Conference Proceedings- Engineering and Mining Geophysics, 2018, vol. 2018, pp. 1-6.

18. Anand R., Lintern M., Hough R., Noble R., Verrall M., Salama W., Balkau J., Radford N. The dynamics of gold in regolith change with differing environmental conditions over time. Geology, 2017, vol. 45, no. 2, pp. 127-130.

19. Fadeev D.I., Balkov E.V., Panin G.L., KarinYu.G. Calibration and rapid transformation of signals of compact equipment of low-depth 
electromagnetic profiling. Geofizika, 2018, no. 6, pp. 52-57. In Rus.

20. Orekhov A.N., Amani M.M. Possibilities of geophysical methods for predicting reservoir fracture. Bulletin of the Tomsk Polytechnic
University. Geo Assets Engineering, 2019, vol. 330, no. 6, pp. 75-84. In Rus.

Received: 27 March 2019.

Information about the authors

Leonid Ya. Erofeev, Dr. Sc., professor, National Research Tomsk Polytechnic University.

Alexander N. Orekhov, Cand. Sc, associate professor, National Research Tomsk Polytechnic University.

Yuliya L. Giryakova, Cand. Sc., senior lecturer, National Research Tomsk Polytechnic University.

Galina V. Erofeeva, Dr. Sc., professor, National Research Tomsk Polytechnic University. 